subcutaneously. The patient education session was supervised by a nurse and a rheumatologist. A 10-question dichotomous questionnaire was then administered to patients to assess the level of uptake of messages passed during the patient education session. The prevalence of correct answers was compared between illiterate and non-illiterate patients.

Results: The mean duration of patient education session is $13 \mathrm{~min}$.

Table I illustrates the results of the correct responses prevalence and the comparison of correct response rates between illiterate and non-illiterate patients.

Table 1. Prevalence of correct responses and comparison of correct response rates between illiterate and non-illiterate patients.

\begin{tabular}{|c|c|c|c|c|}
\hline \multirow[t]{2}{*}{ Questions } & \multirow[t]{2}{*}{$\mathrm{N}=27$} & \multicolumn{2}{|c|}{ Illiterate } & \multirow[t]{2}{*}{$\mathbf{P}$} \\
\hline & & Yes $(\mathrm{N}=11)$ & No $(\mathrm{N}=16)$ & \\
\hline $\begin{array}{l}\text { 1.Do I always have to self-inject on the same day } \\
\text { of the week? }(\%)\end{array}$ & 96,3 & 90,9 & 100 & NS \\
\hline $\begin{array}{l}\text { 2.Should Methotrexate be protected from light } \\
\text { and away from children? (\%) }\end{array}$ & 96,3 & 100 & 93,7 & NS \\
\hline $\begin{array}{l}\text { 3.Can I self-inject anywhere on my thigh and belly } \\
5 \mathrm{~cm} \text { from the navel? (\%) }\end{array}$ & 85,2 & 100 & 75 & NS \\
\hline 4.Is it important to change the injection sites? (\%) & 70,4 & 72,7 & 68,75 & NS \\
\hline $\begin{array}{l}\text { 5.Do I need to pinch the skin before self-injec- } \\
\text { tion? }(\%)\end{array}$ & 92,6 & 100 & 87,5 & NS \\
\hline $\begin{array}{l}\text { 6.Can I always use the same needle for each } \\
\text { injection? (\%) }\end{array}$ & 81,5 & 90,9 & 75 & NS \\
\hline $\begin{array}{l}\text { 7.Do I have to wear gloves to inject Methotrexate? } \\
(\%)\end{array}$ & 81,5 & 90,9 & 75 & NS \\
\hline $\begin{array}{l}\text { 8.Do I have to apply an antiseptic product } \\
\text { (alcohol, Betadine) to the injection site before } \\
\text { self-injecting? (\%) }\end{array}$ & 88,9 & 90,9 & 87,5 & NS \\
\hline $\begin{array}{l}\text { 9.Can I use the rest of the MTX ampoule for the } \\
\text { next injection? (\%) }\end{array}$ & 74,1 & 81,8 & 68,7 & NS \\
\hline 10.Do I tell my doctor if I have side effects? (\%) & 100 & 100 & 100 & NS \\
\hline
\end{tabular}

Conclusion: This study suggests that illiteracy does not affect the assimilation of information given during a patient education session. These preliminary results should encourage the development of patient education programs in our context where illiteracy rate is high.

Disclosure of Interests: None declared

DOI: 10.1136/annrheumdis-2020-eular.5560

\section{THU0642-HPR EVOLUTION OF THE PERCEPTIONS OF RA PATIENTS AFTER EDUCATION PATIENT SESSION TEACHING METHOTREXATE SELF-INJECTION A PROSPECTIVE PILOT STUDY}

S. Afilal ${ }^{1}$, H. Rkain ${ }^{1,2}$, B. Berchane ${ }^{3}$, J. Moulay Berkchi ${ }^{1}$, S. Fellous ${ }^{1}$, T. Fatima $^{2}$ Zahrae $^{1}$, A. Ilham ${ }^{1}$, N. Alami ${ }^{1}$, T. Latifa ${ }^{1}$, N. Hajjaj-Hassouni ${ }^{4}$, F. Allali ${ }^{1} .{ }^{1} E l$ Ayachi Hospital, Faculty of Medicine and Pharmacy of Rabat, Mohammed $V$ University, Rheumatology B, Rabat, Morocco; ${ }^{2}$ Laboratory of Physiology, Faculty of Medicine and Pharmacy of Rabat, Mohammed V University, Rabat, Morocco; ${ }^{3}$ El Ayachi Hospital, Higher Institutes of Nursing Professions and Health Techniques Rabat, Rheumatology B, Rabat, Morocco; ${ }^{4}$ International university of Rabat, Rabat, Morocco

Background: Methotrexate is a gold standard for treatment of RA. In our context, RA patients prefer to be injected by paramedics rather than self-injecting. This can be explained by patients' bad perceptions of self-injection or lack of information. Appropriate self-injection education can therefore be an important element in overcoming these obstacles and improving disease self-management.

Objectives: Compare the RA patients' perceptions on methotrexate self-injection before and after a patient education session.

Methods: Prospective pilot study that included 27 consecutive patients $(81.5 \%$ female, mean age 44.4 years, illiteracy rate $40.7 \%$ ) with RA (median duration of progression of 4 years, mean delay in referral for specialist of 6 months, median duration of methotrexate use of 1 year). The patients benefited from an individual patient education session to learn how to self-inject with methotrexate subcutaneously. The patient education session was supervised by a nurse and a rheumatologist with a control a week later. Perceptions of the reluctance to self-inject and the difficulties encountered by patients were assessed before the patient education session, after the 1 st and 2 nd self-injection of methotrexate using a $10 \mathrm{~mm}$ visual analog scale. Patients also reported their level of satisfaction (10 mm VAS) after the 1st and 2nd self-injection.

Results: The mean duration of patient education session is $13 \mathrm{~min}$.

Table I compares the evolution of the degrees of reluctance to self-injection, the difficulties encountered, and the satisfaction experienced by the patients.
Table 1. Evolution of RA patients' perceptions on the methotrexate self-injection. ( $\mathrm{N}=27)$

\begin{tabular}{lcccc}
\hline & Before & $\begin{array}{c}\text { After the 1 } \\
\text { self-injection }\end{array}$ & $\begin{array}{c}\text { After the 2end } \\
\text { self-injection }\end{array}$ & $\mathbf{p}$ \\
\hline VAS reluctance (0-10mm) & $6,5 \pm 3,6$ & $2,2 \pm 2,9$ & $1,0 \pm 2,3$ & $<0,0001$ \\
VAS difficulty (0-10mm) & $7,5 \pm 2,6$ & $2,5 \pm 2,7$ & $1,0 \pm 1,9$ & $<0,0001$ \\
VAS satisfaction (0-10mm) & - & $8,9 \pm 1,8$ & $9,5 \pm 1,5$ & 0,002 \\
\hline
\end{tabular}

Conclusion: This study suggests the effectiveness of a methotrexate self-injection patient education session in RA patients. It also highlights the value of patient education in rheumatologic care. A large-scale study is necessary to better interpret and complete these preliminary results from this pilot study. Disclosure of Interests: None declared

DOI: 10.1136/annrheumdis-2020-eular.5505

\section{THU0643-HPR PHYSIOTHERAPISTS' ADHERENCE TO OSTEOARTHRITIS CLINICAL GUIDELINES: A NATIONAL ITALIAN SURVEY.}

S. Battista ${ }^{1}$, S. Stefano ${ }^{1}$, M. Serena ${ }^{1}$, M. Testa ${ }^{1}$, A. Dell'isola ${ }^{2} .{ }^{1}$ University of Genoa, Department of Neuroscience, Rehabilitation, Ophthalmology, Genetics, Maternal and Child Health, Genoa, Italy; ${ }^{2}$ University of Lund, Department of Clinical Sciences, Clinical Epidemiology Unit, Lund, Sweden

Background: Osteoarthritis $(O A)$ is the most prevalent joint disease in the world and one of the top causes of disability [1]. OARSI and EULAR guidelines recommend non-surgical interventions as first-line interventions for OA [2]. Despite this, only less than $40 \%$ of people suffering from OA receive the recommended intervention [3]

Objectives: The aim of this study is to investigate to what extent a population of Italian physiotherapists adhere to the OA-guidelines in their clinical practice.

Methods: A quantitative web-based cross-sectional survey was developed according to the Checklist for Reporting Results of Internet E-Survey. The questionnaire was realised in Italy by a panel of physiotherapists, based on the EULAR, OARSI and NICE OA-guidelines. The questionnaire was delivered using REDCap through the Italian Association of Physiotherapists and the University of Genoa newsletters. The questionnaire was divided into two sections. The firs section included 24 statements adapted from the aforementioned guidelines. Participants were asked to express their statement agreement on a scale from 1 (completely disagree) to 5 (completely agree). Participants who partially or totally agreed (score 4-5) were considered to agree with the statements. We defined a $\geq 70 \%$ agreement with a statement as consensus. In the second section, a clinical vignette was presented, illustrating an OA clinical case. Participants had to select, from a list of clinical options, how they would manage this case. Participants were classified as 'Delivering', 'Partially delivering' and 'Non-delivering' the recommended intervention, depending on the recommended or not-recommended interventions chosen.

Results: 812 physiotherapists (age: $36 \pm 13,59$; 48\% women) completed the survey between 26 November 2019 and 9 January 2020. The consensus was achieved for 12 sentences (52\%) out of 23 (Fig. 1). All the statements focussed on exercise, education, and surgical referral received $>70 \%$ of agreement, whereas no consensus was reached for the statements on the clinical diagnostic criteria, for the use of glucosamine or chondroitin products and for the use of topic NSAIDs. In the second section, $20 \%$ of the analysed physiotherapists would deliver an intervention in line with OA guidelines and a $20 \%$ would carry out an intervention that is partially in line with OA guidelines. Conversely, the $40 \%$ of the participants of this survey would include at least a not-recommended intervention, considered, therefore, as 'non-delivering' the recommended intervention (Fig. 2).

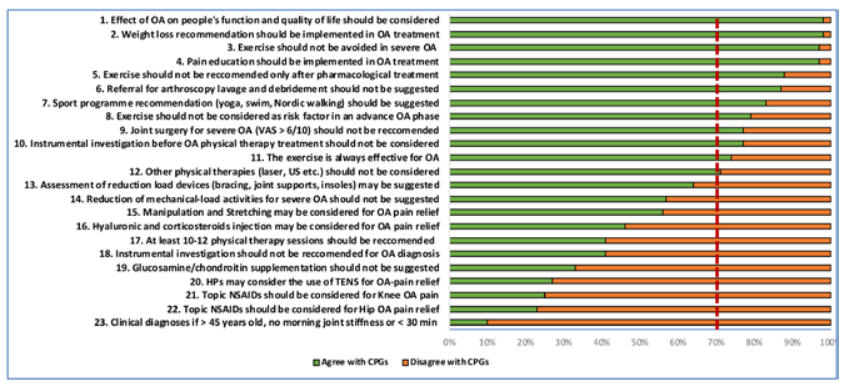

Figure 1. Agreement to Clinical Guidelines (\%) 